\title{
Innovative behaviour: How much transformational leadership do you need?
}

\begin{abstract}
Studies on the effects of transformational leadership on employee innovative behaviour have yielded mixed results. We argue that one possible explanation for these mixed findings is that researchers have assumed a linear relationship between these constructs. In contrast, we suggest that the relationship between transformational leadership and innovative behaviour is non-linear. Specifically, we argue that the positive effects of transformational leadership on innovative behaviour will be stronger at low and high levels of transformational leadership. Moreover, we examine whether the relationship between transformational leadership and innovative behaviour is mediated by knowledge sharing within and between teams. We undertake a constructive replication by testing these hypothesised relationships in two studies: (1) a multi-actor team-level study conducted in the United States, and (2) a longitudinal employee-level study of teachers in the Netherlands. Results of both studies reveal that knowledge sharing mediates the relationship between transformational leadership and innovative behaviour, and that the indirect relationship is curvilinear. We link these findings to leader substitution theory, proposing that employees turn to their peers and other parties when there is an absence of effective leadership.
\end{abstract}

Keywords: transformational leadership, innovative behaviour, knowledge sharing, organisational learning 


\section{Innovative behaviour: How much transformational leadership do you need?}

Organisations increasingly depend on innovative behaviour to address the complex challenges posed by the modern business environment (Janssen, 2005; Nyström, 1990; Scott and Bruce, 1994; Shalley, 1995; West, Hirst, Richter and Shipton, 2004). Innovative behaviour occurs when teams and employees utilize new ideas to enhance a product, service or process (Scott and Bruce, 1994) and involves "both the production of creative ideas as the first stage and their implementation at the second stage" (Anderson, Potočnik and Zhou, 2014).

Theorists have argued that transformational leadership is crucial for innovative behaviour within organisations (Bass, 1985; Eisenbeiss and Boerner, 2010; Eisenbeiss, van Knippenberg and Boerner, 2008; Jung, Chow and Wu, 2003; Sanders and Shipton, 2012). However, empirical studies reveal mixed findings regarding the its effects on innovative behaviour: some reveal a positive relationship (e.g., Eisenbeiss et al., 2008), others a negative one (Basu and Green, 1997; Jaussi and Dionne, 2003), and some studies reveal no relationship (e.g., Kahai, Sosik and Avolio, 2003). As a result, Pieterse et al. (2009) concluded that "empirical evidence for the role of transformational (...) leadership in engendering follower innovative behaviour is scarce and inconsistent".

Eisenbeiss and Boerner (2010) proposed an explanation for these inconsistent effects, suggesting that different mechanisms occur at high and low levels of transformational leadership to stimulate innovative behaviour. At low levels, they argued that while employees lack guidance from their leader, they also have greater intellectual freedom to innovate. At high levels, innovative behaviour occurs because the activities associated with transformational leadership (i.e., vision, intellectual stimulation, and support) encourage creative responses and their effective implementation. Eisenbeiss and Boerner's study 
revealed evidence of a curvilinear relationship between transformational leadership and innovative behaviour.

Our study also tests this curvilinear relationship, and we extend Eisenbeiss and Boerner (2010) work in the following ways. First, given that questions have been raised about the assumption that hierarchical leadership is always important (Kerr and Jermier, 1978), we identify substitutes for leadership as a potential explanation for how employee innovative behaviour may arise given low levels of transformational leadership. Second, we clarify the mechanisms through which transformational leadership influences innovative behaviour. Although scholars have identified some potential mediators of relationships between transformational leadership and its outcomes (Zhu and Akhtar, 2014), less is known about the specific mechanisms that link transformational leadership with innovative behaviour (Gong, Huang and Farh, 2009). In this article, we highlight knowledge sharing as a specific behavioural mechanism influencing innovative behaviour (Sanders and Lin, 2016). Knowledge sharing focuses on the transfer of information among employees and teams to jointly create new insights, and is considered an antecedent of team learning (Sanders and Shipton, 2012).

Researchers have identified communication and information exchange as important when explaining the impact of transformational leadership on innovative behaviour, and have focused on constructs such as team learning and team cohesion (Sanders and Shipton, 2012), organisational learning (García-Morales, Jiménez-Barrionuevo and Gutiérrez-Gutiérrez, 2012; García-Morales, Lloréns-Montes and Verdú-Jover, 2008; Jimenez-Jimenez and Sanz-Valle, 2012) and knowledge-based external support (Gumusluoğlu and Ilsev, 2009). Our study distinguishes knowledge sharing occurring between teams and external stakeholders (Study 1) from knowledge sharing among employees within teams (Study 2). As we later explain, both 
types of knowledge sharing can play an important role in promoting innovative behaviour, depending upon specific contextual demands.

Third, we build on research by Eisenbeiss and Boerner (2010) who utilised a crosssectional research design. Such research designs have questionable internal validity (Cook and Campbell, 1979), as common method variance may affect the observed relationships among constructs (Wright et al., 2001). In addition, cross-sectional designs do not offer insights about whether an antecedent has a short-term or lasting effect. More sophisticated research designs can ameliorate these limitations (Little, 2013). Therefore, we test our three hypotheses in two studies (one multi-actor and one longitudinal) covering different industries and countries. Our second (longitudinal) study also enables us to distinguish between the effects of knowledge sharing that is habitual (i.e., average levels applied consistently over time) versus that which is intermittent (i.e., departures from average levels that occur at a single point in time). The design of our two studies represents a constructive replication (Lykken, 1968), where a research question is assessed using different methodological approaches, samples, and data analytic techniques to test the validity of these methods. In constructive replication, the researcher deliberately avoids using the same methodological approach in later studies to demonstrate the generality of findings.

Overall, our paper contributes to knowledge of the antecedents of innovative behaviour. While innovative behaviour has a range of desirable consequences for an organisation (Janssen, 2005; Scott and Bruce, 1994; Shalley, 1995), it poses a number of risks to employees including exposing them to criticism for questioning existing work methods (Bednall, Sanders and Runhaar, 2014), requiring them to overcome resistance to change (Walker, Armenakis and Bernerth, 2007), and potentially increasing their workload while the change is implemented. Given these barriers, identifying factors that encourage employees' innovative behaviour is vital. Our work also contributes to research on transformational 
leadership by reconciling inconsistent empirical findings regarding its inconsistent effects on innovative behaviour. By testing a curvilinear relationship, we identify the specific functional form of the relationship between transformational leadership and innovative behaviour.

\section{Transformational leadership and innovative behaviour: A linear relationship?}

Transformational leadership is a multidimensional construct that encompasses four behavioural sub-dimensions: idealized influence, inspirational motivation, intellectual stimulation, and individualized consideration (Bass, 1985, 1990). Idealized influence (charisma) is displayed when leaders "provide(s) vision and sense of mission, instils pride, gains respect and trust". Inspirational motivation refers to leadership behaviours that add nonintellectual, emotional qualities to the influence process, such as displaying an action orientation, seeking to build employees' confidence through verbal communications, and inspiring belief in the cause (Rafferty and Griffin, 2004). Individualized consideration involves providing support for followers (Yukl, 1999), such as mentoring or coaching, monitoring performance and assigning appropriately challenging tasks. Intellectual stimulation refers to efforts to motivate followers to perceive and approach challenges in new ways. Transformational leadership goes beyond transactional leadership, which is focused on establishing an exchange relationship with followers to achieve specified goals for rewards but is considered While transactional leadership is an important basis for effective leadership, it is insufficient to motivate innovative behaviour (Zhu and Akhtar, 2014).

Based on findings that high levels of transformational leadership are associated with innovative behaviour, researchers have argued that high levels of transformational leadership inspire employees to go beyond expected performance levels (e.g., Gumusluoğlu and Ilsev, 2009; Jung and Wickrama, 2008). Mumford, Scott, Gaddis and Strange (2002) suggested that innovation requires a persuasive visionary leader, who is willing to champion an idea and is capable of influencing others in the organisation to adopt it. Similarly, Gong et al. (2009) 
argued that inspirational motivation should stimulate employees' intrinsic motivation on a creative task and increase creative self-efficacy. Sarros, Cooper and Santora (2008) argued that intellectual stimulation encourages employees to consider alternative perspectives, devise new ideas, and experiment with new approaches. Finally, Gumusluoglu and Ilsev (2009) suggested that individualized consideration enables leaders to better understand employees' needs, skills and aspirations, providing encouragement and recognition for creativity.

A neglected question concerns whether transformational leadership linearly exerts an influence on innovative behaviours at high, medium and low levels, or whether the relationship is curvilinear such that it is stronger at high and low levels and weaker at moderate levels. Answering this question might go some way towards addressing inconsistencies in the literature that currently hold back theorising and the scope for practical guidance in this area (Eisenbeiss and Boerner, 2010; Eisenbeiss et al., 2008; Pieterse et al., 2009).

To explain the seemingly counterintuitive idea that low levels of transformational leadership might result in high levels of innovative behaviour, we draw on substitutes for leadership theory. Kerr and Jermier (1978) argued that certain factors 'substitute' for hierarchical leadership, or negate a leader's ability to influence employee satisfaction and performance. This is supported by research on innovative behaviour which indicates that cognitive, affective and motivational support for creativity and innovation may additionally be derived from personal and work-related contexts (Amabile et al., 1996; Anderson et al., 2014).

Kerr and Jermier (1978) identify several substitutes for leadership including employee, task, and organisational characteristics. In the current research, we focus on two different groups of professionals. Relevant to this context, Kerr and Jermier argued that professional employees tend to cultivate horizontal rather than vertical relationships; they place greater 
value on peer feedback compared to hierarchical assessment. Without effective leadership, such employees are likely to cultivate relationships that offer task-related feedback and emotional support, obviating reliance on hierarchical supervisory arrangements, and providing motivation to engage in innovative behaviour. Kerr and Jermier also identify a need for independence and an indifference to organisational rewards as additional substitutes for leadership. Professional employees are likely to report both characteristics, as they focus on their professional bodies to provide status and other rewards. We argue that such employees will look beyond hierarchical leaders and to their peers for vision and inspiration in delivering work-related outcomes including innovative behaviours. Such employees may act as role models whom their peers seek for task-related feedback and support. Thus, the positive effects on innovation may be seen across the whole work group even in the absence of transformational leadership.

In summary, high levels of transformational leadership will support innovative behaviours through the provision of vision, inspiration, intellectual stimulation, and individualized consideration. When transformational leadership is low, professional employees are likely to engage in greater innovative behaviour if there are 'substitutes' for leadership (Kerr and Jermier, 1978). Conversely, modest levels of transformational leadership may represent a sub-optimal context which raises employees' expectations of support and direction while taking attention away from facets of the work environment that could otherwise inspire innovative behaviours (e.g., developing supportive peer relationships with feedback opportunities). As such, we propose:

Hypothesis 1: Transformational leadership will have a curvilinear effect on innovative behaviour, such that innovative behaviour will be stronger at low and high levels of transformational leadership. 


\section{The mediating role of knowledge sharing}

Knowledge sharing has been defined as information exchange, and includes giving feedback, discussing errors, and identifying the best approach to tasks (Bock, Zmud, Kim and Lee, 2005; Lin, 2007b). Mutual exchange frequently leads to the creation of new knowledge (Van den Hooff and de Ridder, 2004). Thus, knowledge sharing implies collaboration of employees towards common goals (Boland and Tenkasi, 1995). It shares similarities with other reciprocal behaviours (Ipe, 2016), such as prosocial and organisational citizenship behaviours (Frey, 1993). As a type of informal learning (Bakkenes, Vermunt and Wubbels, 2010), knowledge sharing helps employees to gain new insights, as it is usually relevant to specific work needs and divisible into small time chunks (Hoffman, 2005). In addition, knowledge sharing drives employee performance, since it may entail challenging established norms, practices, or habits (Edmondson, 1999), leading to the questioning of assumptions and triggering of new ideas.

In this study, we distinguish knowledge sharing between teams and external parties from knowledge sharing among employees within teams. Knowledge sharing between teams is likely to promote innovative behaviour by providing a better understanding of the broader business environment. For example, knowledge sharing can enhance employees' understanding of their customers' preferences (Hu, Horng and Sun, 2009), providing an impetus to make improvements to products, services or work methods. This type of knowledge sharing also helps employees to draw on multiple perspectives, enabling them to frame ideas in new ways, connect diverse perspectives, and challenge existing ways of working (Lakshman, 2005; Liao, Fei and Chen, 2007; Smith, Collins and Clark, 2005). Such discussions may spark ideas and help with the implementation of new ideas.

Knowledge sharing within teams is also likely to promote innovative behaviour, as greater task knowledge enhances potential for creativity (Amabile et al., 1996). In addition, 
knowledge sharing facilitates the capture and transfer of experiences between employees (Lin, 2007a), which is particularly important for less experienced employees who lack relevant knowledge. Moreover, knowledge sharing also may help team members work together more effectively on creative tasks. Previous research has identified team learning and cohesiveness as mediators of the relationship between transformational leadership and innovative behaviour (Sanders and Shipton, 2012). Knowledge sharing may facilitate these processes by helping members to agree on shared goals, prioritize and coordinate activities, and access important information more readily (Gilson and Shalley, 2004).

Relatively little is known about whether leadership styles influence either betweengroup or within-group knowledge sharing (Wang and Noe, 2010), but transformational leaders may encourage both. Transformational leaders influence norms of reciprocity (Gagné, 2009), and articulate common goals that encourage collaboration. They also act as role models for sharing knowledge. By sharing a common organisational vision, they may also act as facilitators of communication between departments. Furthermore, transformational leaders engender trust with their team members (Jung and Avolio, 2000; Pillai, Williams, Lowe and Jung, 2003) and commitment to a common purpose (Zohar and Tenne-Gazit, 2008). If employees trust each other, they are more likely to divulge work-related information and be less apprehensive about exposing their methods to negative evaluation (Hsu, Ju, Yen and Chang, 2007). In addition, some employees are reluctant to give up unique knowledge because they may lose their performance advantage in the workplace (Renzl, 2008). If a leader builds trust and emphasizes norms of collaboration, employees are more likely to divulge unique knowledge.

On the other hand, low levels of transformational leadership should also encourage knowledge sharing, particularly if employees experience a lack of direction. Cabrera, Collins and Salgado (2006) argued that if employees report a high level of individual responsibility 
for their work, they would be motivated to seek out more efficient ways to perform their job. In the absence of detailed direction, employees are likely to seek guidance from alternative sources of support (Kerr and Jermier, 1978). Both concerns would likely motivate greater knowledge sharing.

Overall, we expect that transformational leadership will encourage knowledge sharing, which in turn will elicit innovative behaviour. Based on the above reasoning, we also propose that transformational leadership has a curvilinear effect on knowledge sharing. Specifically, we propose:

Hypothesis 2: Transformational leadership has a curvilinear effect on knowledge sharing, such that it will be greater at low and high levels of transformational leadership.

Hypothesis 3: Knowledge-sharing will mediate the relationship between transformational leadership and innovative behaviour.

\section{Current studies}

We test the three hypotheses in two studies, which are conducted within different industries and countries, and use different research designs. Study 1 focuses on teams, and investigates knowledge sharing between teams and external stakeholders (e.g., experts in other teams, customers, and suppliers) as a mediator of the transformational leadership and innovative behaviour relationship. We chose an externally-oriented measure of knowledge sharing, as we regarded employees' understanding of these stakeholders' needs to be essential to effective innovative behaviour. This first study employs a two-wave, multi-actor design, and investigates a sample obtained from multiple industry groups within the United States.

Study 2 focuses on employees, and investigates knowledge sharing within teams. This study involves a three-wave design, and investigates a sample of teachers within vocational educational training schools in the Netherlands. It examines the role of knowledge sharing 
within teams, and distinguishes between knowledge sharing that is habitual (i.e., each person's average level over time) versus intermittent (i.e., departures from average levels occurring at a single point in time). For example, if an employee's average level of knowledge sharing was 3 on a 5-point scale, and they reported ratings of 2.5 and 3.5 at Times 1 and 2 , the fluctuations would be equal to -0.5 and +0.5 . Finally, given teachers' focus on working with internal stakeholders (i.e., students and other teachers), we chose an internallyoriented measure of knowledge sharing.

\section{Study 1}

\section{Method}

Participants and Procedure. The sample consisted of 76 teams, each from a different organisation. The line manager of each team was recruited through an online cognitive laboratory (Jackson, 2010) (www.ywedo.com/lab.asp), which is designed to administer questionnaires and cognitive tasks to research participants. Participants completed a larger battery of tests than reported in this study. Each manager provided self-ratings of their leadership style. Managers invited up to three raters (each manager's supervisor, a colleague and a subordinate), who provided 360-degree leadership ratings. Each manager also invited up to three subordinates (team members), who provided ratings of knowledge sharing and innovative behaviour.

There were two waves of data collection. We used 76 cases in which there were data from both waves (reduced from 158 at Wave 1). In total, there were 76 line-managers, 193 additional raters (62 supervisors, 67 colleagues and 64 subordinates), and 201 team members in the sample. Managers were paid US\$25 for their participation.

At Wave 1, 360-degree ratings of transformational leadership were collected from the line managers and the additional raters. At Wave 2 (completed an average of 133.24 days later; $\mathrm{SD}=11.76$ ), the team members provided ratings of knowledge sharing and innovative 
behaviour. We used maximum likelihood estimation to estimate model parameters from all available data, which is more efficient and produces more accurate estimates than listwise or pairwise deletion (Enders, 2001). Two teams were removed as all three members provided identical ratings for knowledge sharing and innovative behaviour measures.

Measures. All constructs were measured using published scales. Each measure was reliable, with a Cronbach's alpha coefficient over .70. We also assessed inter-rater reliability among team members by calculating intraclass correlation coefficients $(I C C)$, where $I C C(1)$ indicates the ratio of between-group variance to total variance, and $I C C(2)$ indicates the reliability of the group mean (Bliese, 2000). We assessed agreement among team members using the $r_{W G(J)}$ index, which indicates the absolute consensus in scores between multiple raters (LeBreton and Senter, 2007). Based on the high levels of interrater reliability (smallest $\operatorname{ICC}(1)=.46$ and $\operatorname{ICC}(2)=.74)$ and agreement (smallest mean $\left.r_{W G(J)}=.89\right)$, we aggregated each measure to the team level by calculating the group mean of each indicator. We used a single response measure for teams where only one respondent was available. Cronbach's alpha coefficients, $I C C(1), I C C(2)$ and $r_{W G(J)}$ agreement indices are reported in Table 1.

Transformational leadership (TFL) of each line manager was measured using the 16item multifactor leadership questionnaire (MLQ form 6S; Bass and Avolio, 1992). The measure comprises four subscales that are each assessed with four items, including idealized influence (e.g.,: "[The manager] emphasizes the importance of having a collective sense of mission”), intellectual stimulation (e.g., "[The manager] seeks differing perspectives when solving problems"), inspirational motivation (e.g., "[The manager] talks enthusiastically about what needs to be accomplished"), and individualized consideration (e.g., "[The manager] treats others as individuals rather than just as a member of a group"). To reduce the indicatorto-sample ratio, we applied the facet-representative parcelling approach (Little, Cunningham, Shahar and Widaman, 2002) to combine all items associated with each sub-dimension by 
calculating their mean. We used these parcels as manifest indicators to represent the theorised structure of transformational leadership. Responses ranged from 1 ("Not at all") to 5 ("Frequently, if not always").

Transformational leadership ratings were obtained from multiple sources, including each participant's self-ratings, their manager, a colleague, and a direct report. In total, 53 $(70 \%)$ managers were rated by all four raters, $16(21 \%)$ were rated by two or three raters, and seven (9\%) were only rated by a single person. The relationship between transformational leadership and the number of raters was not significant $(r=.04, n . s$.$) .$

Knowledge sharing with external parties was measured using Garvin, Edmondson and Gino's (2008) information transfer scale. We used the four items associated with meeting with and learning from other parties, removing non-relevant items related to the team's information dissemination and conducting team reflection. Responses to each item ranged from 1 ("Highly inaccurate") to 5 ("Highly accurate"). An example item is: "This unit has forums for meeting with and learning from experts from other departments". Knowledge sharing was rated by three members in $60(79 \%)$ teams, two members in $5(7 \%)$, and one member in $11(14 \%)$ teams. The correlation between the number of raters and reported levels of knowledge sharing was small and non-significant $(r=.04, n . s$.$) .$

Innovative behaviour was measured using a nine-item scale (Van der Vegt and Janssen (2003). Responses to each item ranged from 1 ("Never") to 5 (“Always"). This measure comprises three subscales representing idea generation (e.g., "Creating new ideas for improvements"), idea promotion (e.g., "Mobilizing support for innovative ideas") and idea realization (e.g., "Transforming innovative ideas into useful applications"). Using the facetrepresentative approach, the items associated with each subscale were aggregated into parcels by calculating their mean. Innovative behaviour was assessed by up to three members from each team and was analysed as an employee-level variable. In total, innovative behaviour was 
rated by three members in $60(79 \%)$ teams, two members in five $(7 \%)$, and one member in 11 $(14 \%)$ teams. The correlation between the number of raters and reported levels of innovative behaviour was small and non-significant $(r=.02, n . s$.$) .$

Controls. Control variables were assessed by managers and included company size, manager tenure and manager seniority. Previous research has reported a relationship between the number of workers employed by a firm and innovation (e.g., Laforet, 2008; Wagner and Hansen, 2005). Similarly, manager tenure has been found to be associated with innovative behaviour (Damanpour and Schneider, 2008). Manager seniority also was included as we expected that top managers would have greater access to resources and internal and external networks to support knowledge sharing and innovative behaviour.

\section{Results}

All analyses (Studies 1 and 2) were conducted in Mplus 7.4 using the maximumlikelihood robust (MLR) estimator. Table 1 presents descriptive statistics, including observed variable means, standard deviations, correlations, reliability coefficients, $I C C \mathrm{~s}$ and $r_{W G(J)}$. The table shows that TFL was positively related to both knowledge sharing and innovative behaviour. Knowledge sharing was positively related to innovative behaviour.

\section{Insert Table 1 about here}

Confirmatory factor analysis. To assess our hypothesized measurement model, we analysed the items (and parcels) from the transformational leadership, knowledge sharing and innovative behaviour scales. We aggregated all individual-level scales to the team level by calculating their group average, and then used confirmatory factor analysis to evaluate the hypothesised factor structure. Close model fit is indicated by a non-significant chi-square, a comparative fit index (CFI) above .90 , a root mean square error of approximation (RMSEA) 
below .08, and a standardized root mean square residual (SRMR) below .08 (Hox, 2010; Hu and Bentler, 1999). Although the chi-square was significant, $\chi^{2}(\mathrm{df} 41)=76.032$, the other indices indicated a close fit to the data, $\mathrm{CFI}=.925, \mathrm{RMSEA}=.065, \mathrm{SRMR}=.068$. We also tested an alternate model in which knowledge sharing and innovative behaviour were combined on a single factor, but this produced poor fit, $\chi^{2}(\mathrm{df} 43)=186.474, \mathrm{CFI}=.693$, $\mathrm{RMSEA}=.129, \mathrm{SRMR}=.122$. Table 2 presents the standardised factor loadings from the hypothesised model.

Insert Table 2 about here

Structural model. To assess the effects of transformational leadership on knowledge sharing and innovative behaviour, we tested a structural model. The model depicts the effects of transformational leadership on aggregated knowledge sharing and innovative behaviour at the team level. To assess the non-linear effects of transformational leadership, we estimated a quadratic term using the latent moderated structural equations method (LMS; Klein and Moosbrugger, 2000). As fit statistics are unavailable for LMS, we first estimated a model without the quadratic term, which indicated close fit to the data: $\chi^{2}(\mathrm{df}=65)=113.667$, $\mathrm{CFI}=.914, \mathrm{RMSEA}=.061, \mathrm{SRMR}=.064$. To assess whether introducing the quadratic term reduced the parsimony of the second model, we compared the Akaike Information Criterion (AIC) and sample-size adjusted Bayesian Information Criterion (BIC) of the models. There were no substantial differences between the models (original model: AIC $=1916.95$, $\mathrm{BIC}=1924.25 ;$ second model $:$ AIC $=1917.77, \mathrm{BIC}=1925.34)$, suggesting the additional complexity introduced by the quadratic term was balanced by the information it contributed. Figure 1 presents the hypothesised model and results. 
Insert Figures 1 and 2 about here

Hypothesis 1 predicted a non-linear relationship between transformational leadership and innovative behaviour. H1 was not supported, as both the linear and the quadratic effect of transformational leadership were non-significant (Figure 2, Panel A). Hypothesis 2 predicted a non-linear relationship between transformational leadership and knowledge sharing. In support of $\mathrm{H} 2$, both the linear and the quadratic effects of transformational leadership were positive and significant. To determine the point at which transformational leadership became a stronger predictor, we used calculus to identify the vertex of the quadratic regression equation from its first derivative. As depicted in Figure 2 (Panel B), this point occurred at 3.7, which was slightly below the mean of 4.15 on the 5 -point scale.

In support of Hypothesis 3, knowledge sharing was positively related to innovative behaviour. The indirect effect of transformational leadership on innovative behaviour via knowledge sharing was significant for the linear term $(\beta=.24, p=.045)$, and it approached significance for the quadratic terms $(\beta=.26, p=.072)$. Regarding the controls, company size was negatively related to innovative behaviour: $\beta=-.23, p<.001$. Manager seniority was positively related to knowledge sharing: $\beta=.33, p=.037$. The effects of tenure were not significant.

\section{Discussion (Study 1)}

The results partially support hypotheses. Transformational leadership displayed a significant curvilinear relationship with knowledge sharing, but not with innovative behaviour. However, transformational leadership had a curvilinear indirect effect on innovative behaviour via knowledge sharing. Specifically, the positive relationship between 
transformational leadership and knowledge sharing becomes stronger at higher levels of transformational leadership.

In this first study, we assessed knowledge sharing as the exchange of information between teams and external parties (including outside experts, customers and suppliers). These findings suggest that teams managed by transformational leaders will engage in knowledge sharing interactions with external parties. Given the non-linear relationship, the results suggest that teams were encouraged to engage in these behaviours when managers exhibited above average transformational leadership. High levels of knowledge sharing with external parties in turn stimulated teams to engage in innovative behaviour.

\section{Study 2}

The purpose of Study 2 is to constructively replicate (Lykken, 1968) Study 1 by investigating the mediating effects of knowledge sharing that occurs among employees within teams. This study additionally examines the study hypotheses using a longitudinal design within a different (educational) context. On an exploratory basis, it also distinguishes between the effects of knowledge sharing that is habitual (i.e., occurs consistently over time) versus intermittent (i.e., fluctuations at a single point in time).

The distinction between habitual and intermittent behaviour has important theoretical and practical implications. In partitioning the variance into time-invariant and time-varying factors, the analysis reveals the extent to which a behaviour or characteristic is trait- or statelike within a particular context (Cole, Martin and Steiger, 2005). This analysis also indicates whether the time-invariant or time-varying component has stronger effects on other outcomes. From a practical standpoint, habitual behaviour is likely to be difficult to shift, whereas intermittent behaviours should be more malleable. For instance, managers would be advised to recruit employees who frequently engage in desired habitual behaviours, and offer ongoing incentives and situational support to encourage intermittent behaviour. 


\section{Method}

Participants and Procedure. Three waves of survey data were collected from employees in six vocational educational training (VET) high schools in the Netherlands. The VET schools were contacted through the human resources and research managers within the schools, who in turn invited unit managers, team leaders and teachers to participate in the study. In total, there were 60 teams, ranging from 1 to 20 respondents $(M=6.65)$. Each wave of data was collected a year apart, in 2010, 2011 and 2012. Thus, the data were ordered into three levels: time points (Level 1) nested in individuals (Level 2), nested in teams (Level 3).

There were 399 participants at the first wave (response rate 53.3\%), 248 at the second wave, and 199 at the third wave. The majority (66\%) of the sample was male, and the mean age of the participants was 49.8 years $(\mathrm{SD}=9.7)$. In this sample, $84.8 \%$ indicated their primary role was as a teacher, $9.9 \%$ as a teaching assistant, and 5.3\% as "other". Regarding their educational background, $71.9 \%$ reported having received a higher professional education degree, $16.7 \%$ received a scientific education degree, and $11.3 \%$ a vocational education degree. Most of the sample (60.4\%) had a full-time equivalent (FTE) workload; $25.3 \%$ had a $60-80 \%$ FTE, $9.4 \%$ had a $40-60 \%$ FTE, $4.1 \%$ had an FTE of $20-40 \%$, and $0.7 \%$ had an FTE of less than $20 \%$.

Measures. We employed a different set of measures to Study 1. These measures were designed for an educational context. Responses were measured using five-point Likert scales $(1=$ totally disagree, $5=$ totally agree $)$. Cronbach's alpha reliability coefficients (reported in Table 3) were greater than .71 for all measures across all three waves.

Transformational leadership was measured using a scale developed by Geijsel, Sleegers, Stoel and Krüger (2009), which is designed to measure transformational leadership in an educational context. The scale measures similar constructs to the MLQ, apart from the omission of idealized influence (Bass and Avolio, 1992). The measure includes a five-item 
subscale of inspirational motivation referred to as "vision" (example item: "My supervisor makes use of all possible opportunities to communicate the department's vision"), a threeitem subscale of individualized consideration referred to as "support" (example item: "My supervisor listens carefully to the ideas of team members"), and a three-item scale designed to measure intellectual stimulation (example item: "My supervisor encourages teachers to think about ways to improve this school"). The items associated with each subscale were aggregated into parcels by calculating their mean. All employees within a team rated their manager. We found that a high level of reliability and agreement within each team, $\left(I C C(1)=.33, \operatorname{ICC}(2)=.77\right.$, and mean $\left.r_{W G(J)}=.89\right)$ and therefore we aggregated this measure and analysed it as a team-level variable.

Knowledge sharing within teams was measured using a 4-item scale from Van Woerkom (2003). It assesses the extent to which employees share knowledge and ask for advice. An example item is: "I share my knowledge and experiences with my team members on a regular basis". Employees provided self-ratings at all three waves on the same set of items. We analysed both the between-person (time-invariant) and within-person (timevarying) components of these repeated assessments.

Innovative behaviour was measured using a 4-item scale (De Jong and Den Hartog, 2005). It measures the extent to which employees seek new methods and creative ideas, and promote them to other colleagues. An example items is: "I come up with creative solutions for problems". Employees provided self-ratings of innovative behaviour in all waves. We analysed the between- and within-person components of these repeated assessments.

Demographic variables were included in the analysis as controls. These variables included gender $(0=$ female, $1=$ male $)$ and tenure. Tenure was measured on an 8 -point ordinal scale, ranging from 1 (less than half a year) to 8 (more than 20 years). We included 
tenure based on the argument posed by Hammond et al. (2011) that experienced employees have acquired extensive knowledge to draw innovative ideas.

\section{Results}

Descriptive statistics, including observed variable means, standard deviations, correlations and reliability coefficients, are presented in Table 3. Transformational leadership was positively associated with knowledge sharing in all three waves. In contrast, transformational leadership was not significantly associated with innovative behaviour at any of the time points. Tenure was negatively associated with knowledge sharing at Waves 2 and 3.

Insert Table 3 about here

Confirmatory factor analysis. To develop a measurement model, we conducted a series of confirmatory factor analyses using the approach recommended by Widaman, Ferrer and Conger (2010). Details of the procedure are presented in Appendix 1. The final (strict invariance) model closely fitted the data $\chi^{2}(\mathrm{df}=303)=420.355, \mathrm{CFI}=.971$, RMSEA $=.024$, SRMR $=.054$. Standardized loadings are presented in Table 4.

To assess the discriminant validity of each factor, we constrained the correlation between each pair of factors to 1 and examined the change in model fit. In all cases, imposing this constraint produced significantly worse model fit; largest $r=.72$ (innovative behaviour at wave 2 and innovative behaviour at wave 3$), \Delta \chi^{2}(\mathrm{df}=1)=44.732, p<.001$. This finding implies that each latent variable was measuring a factor that was empirically distinct from the other factors in the model. 
Insert Table 4 about here

Longitudinal structural analysis. To investigate the effects of each manager's level of transformational leadership over time, the data were analysed using a random intercepts cross-lagged panel model (RI-CLPM; Hamaker, Kuiper and Grasman, 2015). RI-CLPM is an extension of a traditional cross-lagged panel model. It decomposes repeated assessments of the same variable into three parts: (1) the sample mean at each point in time, (2) a component representing stable between-person differences across time (i.e., time-invariant, habitual behaviour), and (3) a component representing within-person differences at each point in time (i.e., time-varying, intermittent behaviour). In a single measurement, all three components are confounded. In contrast, RI-CLPM allows investigation of the antecedents and effects of each component across repeated assessments. We further extend the RI-CLPM by adapting it to a multilevel framework. Specifically, we allow component (1) to vary across teams, and we investigate transformational leadership as a team-level antecedent of knowledge sharing and innovative behaviour. We chose RI-CLPM instead of a multilevel latent growth model (e.g., McArdle, 2009), as we did not hypothesise systematic change in any of the variables as a function of time.

This model and results are presented in Figure 3 and yields a very good fit to the data, $\chi^{2}(\mathrm{df}=34)=33.960, p=.46, \mathrm{CFI}=1.000, \mathrm{RMSEA}=0$, SRMR-Between $=.169$, SRMRWithin $=.029$. Across the three waves, the between-person (habitual behaviour) component accounted for $54.2 \%$ of the variance in knowledge sharing and $49.3 \%$ in innovative behaviour. 
Insert Figures 3 and 4 about here

Hypothesis 1 predicted that transformational leadership would have a non-linear effect on innovative behaviour. Although the trend line showed some curvature (Figure 4, Panel A), both the linear and quadratic effects were non-significant. The second hypothesis predicted that transformational leadership would have a non-linear effect on knowledge sharing. This hypothesis was supported: employees reported higher levels of knowledge sharing at low and high levels of transformational leadership (Figure 4, Panel B). Both the linear and quadratic effects of transformational leadership were both positive and significant. This relationship becomes positive around the mid-point of the transformational leadership scale (i.e., the vertex occurs at 2.8 , compared to the mean of 3.33 on a 5-point scale).

Hypothesis 3 proposed that knowledge sharing would mediate the relationship between transformational leadership and innovative behaviour. This hypothesis was supported, with the between-person (habitual) component of knowledge sharing positively related to innovative behaviour. The indirect effect of transformational leadership on innovative behaviour via knowledge sharing was significant for both the linear $(\beta=.13, p=.005)$ and quadratic $(\beta=.12, p=.009)$ terms.

We also examined the relationship between the within-person (intermittent) components of knowledge sharing and innovative behaviour. The autoregressive paths for knowledge sharing were negative, but did not reach significance. The innovative behaviour autoregressive path and the cross-lagged paths were not significantly different from zero. At each point in time, the residual covariances between knowledge sharing and innovative behaviour were positive but did not reach significance. These results suggest that after accounting for stable between-person differences, fluctuations in knowledge sharing and 
innovative behaviour do not stimulate later participation in either activity at subsequent time points. Removal of the within-person effects did not worsen model fit according to the Wald statistic, $\Delta \chi^{2}(\mathrm{df}=4)=5.992, p=.19$. With regard to the control variables, the effects of tenure and gender were small and non-significant (all $p$ values $>.10$ ).

\section{Discussion (Study 2)}

Using a longitudinal, employee-level design, the purpose of the second study was to constructively replicate Study 1. Consistent with Hypothesis 2, findings indicate that the relationship between transformational leadership and knowledge sharing is curvilinear. Like the previous study, knowledge sharing was strongest when transformational leadership was above the mean (3.33 out of 5). Transformational leadership also appears to be indirectly related to innovative behaviour via knowledge sharing (Hypothesis 3). Greater knowledge sharing among team members appears to create conditions that favour innovative behaviour, such as through the transfer of experiences (Lin, 2007b), the building of task knowledge (Amabile et al., 1996), and after-action reviews to identify improvements to existing methods (Ellis and Davidi, 2005).

We observed that the within-person relationships between knowledge sharing and innovative behaviour were non-significant. This finding implies that departures from baseline levels of both activities do not predict later increases or decreases in participation. However, the relationship between the stable, between-person components of knowledge sharing and innovative behaviour was significant. Collectively, these findings indicate that habitual knowledge sharing is associated with participation in innovative behaviour.

Habitual knowledge sharing is weakest at medium levels of transformational leadership. At such levels, managers may send unclear or contradictory signals about their priorities (cf. Connelly, Certo, Ireland and Reutzel, 2010), leaving employees uncertain about whether they should participate in this activity. At lower levels of transformational leadership, knowledge 
sharing was higher. As we later discuss, with reference to substitutes for leadership theory (Kerr and Jermier, 1978), employees may revert to their own preferred means of knowledge sharing in the absence of clear directives.

\section{General Discussion}

Our two studies provide evidence in support of the hypotheses, using data from different countries and using two different data collection methods. Results of both studies reveal a curvilinear relationship between transformational leadership and knowledge sharing. These effects are similar for knowledge sharing between teams and other stakeholders and knowledge sharing within teams. In both studies, the relationship between transformational leadership and innovative behaviour was fully mediated by knowledge sharing. Moreover, the findings of Study 2 indicate that only habitual participation in knowledge sharing over time is associated with greater innovative behaviour.

In both studies, Hypothesis 1 was not supported. Although unexpected, this finding underscores the importance of knowledge sharing both within and between teams as a vital precondition for innovative behaviour. In a commercial setting, knowledge sharing with external stakeholders is vital for employees to understand organisational strategy, customer needs and the broader business environment (Hu et al., 2009). In an educational setting, knowledge sharing within the organisation (i.e., between teachers, and between teachers and students) is part of best practice and a driver of innovative behaviour (Hou, Sung and Chang, 2009). Knowledge sharing between employees also assists them in accessing existing informational resources which is likely to stimulate new, innovative ideas (García-Morales et al., 2008).

Hypothesis 2 was supported in both studies: transformational leadership had a nonlinear effect on knowledge sharing. Specifically, at above-average levels of transformational leadership, its relationship with knowledge sharing became stronger. In Study 2, knowledge 
sharing increased at very low levels of transformational leadership, whereas this pattern was not observed in Study 1. This discrepancy may be due to a smaller range of transformational leadership ratings in Study 1 (which ranged from 3.1 to 4.9) than in Study 2 (1.2 to 4.5). Range restriction may be an artefact of recruiting participants through their managers, as managers may choose assessors who provide favourable leadership ratings. Consequently, range restriction may explain the absence of the left side of the U-shaped curve that was only observed in the second study.

Support for Hypothesis 3 in both studies provides evidence that knowledge sharing mediates the relationship between transformational leadership and innovative behaviour. Study 1 focused on knowledge sharing between teams and experts from other departments, and outside of the organisation, customers and clients, and suppliers. Conversely, Study 2 focused on knowledge sharing between individual employees within teams. Despite these differences, the findings of both studies are consistent in demonstrating that knowledge sharing provides a two-way framework for sharing and enacting new ideas. Greater levels of knowledge sharing likely provides better alignment with situational requirements and allows individuals to challenge the status quo (Lakshman, 2005; Liao et al., 2007; Runhaar, Sanders and Yang, 2010; Smith et al., 2005). Knowledge sharing may provide a behavioural mechanism through which transformational leaders spread new ideas, thereby improving current practices and benefitting the organisation.

\section{Theoretical contributions and managerial implications}

Our study adds to the literature on how transformational leadership effects team and employee innovative behaviour. Specifically, we identify knowledge sharing as a behavioural mechanism that mediates the relationship between transformational leadership and innovative behaviour. The curvilinear indirect effect (i.e., via knowledge sharing) between transformational leadership and innovative behaviour provides a likely explanation for 
inconsistent results previously reported (e.g., Eisenbeiss et al., 2008). Transformational leadership ratings in the low range produce a negative linear relationship, whereas ratings in the high range produce a positive relationship. Conversely, samples with ratings that cover more of the spectrum (e.g., Study 2) produce a null relationship unless quadratic or mediational effects are considered.

This non-linear relationship implies that different mechanisms are responsible for knowledge sharing at both ends of the transformational leadership spectrum. At the high end, we suggest that the combination of the different facets of transformational leadership produces a positive, synergistic effect on innovative behaviour. At the low end, we suggest the absence of a directive manager allows other contextual conditions to become salient and enables employees to work autonomously and collaborate with others. In Study 2, most employees were highly experienced, and could work autonomously to devise and implement innovative solutions. We recommend that future studies investigate the factors that enable successful innovative behaviour in such situations, such as the individual capabilities of employees, their autonomy, support from colleagues, as well as access to knowledge sharing and other informational resources.

Our study clarifies the mechanism by which transformational leadership influences innovative behaviour. Previous studies have noted that innovative behaviour is increased through group cohesion (Jaussi and Dionne, 2003), team learning (Sanders and Shipton, 2012), support for innovation (Eisenbeiss et al., 2008), and organisational learning (GarcíaMorales et al., 2008). Our study builds on this literature by pinpointing knowledge sharing as a specific employee behaviour that facilitates innovative behaviour. By focusing on a single behavioural mechanism, our study provides a potentially more straightforward explanation for the positive effects of transformational leadership on innovative behaviour, and points to practical actions managers and teams can take to enhance innovative behaviour. Results 
provide evidence that both knowledge sharing between and within teams facilitates innovative behaviour.

Our study suggests several practical implications for managers. First, high levels of transformational leadership are most effective in stimulating both knowledge sharing and innovative behaviour. Ideally, managers should display all aspects of transformational leadership to encourage employees, while also encouraging employee independence and freedom of thought (Eisenbeiss and Boerner, 2013). As knowledge sharing is an important antecedent of innovative behaviour, managers should encourage interactions among teammates and important external stakeholders, including other departments, customers, suppliers and professional contacts. By drawing on ideas, expertise and knowledge of the business environment, employees should be better able to engage in innovative behaviour. Moreover, Study 2 indicates that only habitual (but not intermittent) participation in knowledge sharing will increase innovative behaviour. Thus, managers should focus on embedding a culture and routines that encourage frequent knowledge exchanges among employees and important external stakeholders (cf. Argote, McEvily and Reagans, 2003; Senge, 1997). In contrast, short-term or unsystematic initiatives to increase knowledge sharing (e.g., isolated workshops, infrequent collaborations) are unlikely to facilitate innovative behaviour.

\section{Limitations and opportunities for future research}

Recognizing conceptual and empirical problems associated with transformational leadership as potential limitations of our study (e.g., Van Knippenberg and Sitkin, 2013; Yukl, 1999), we sought to minimize these issues by using the MLQ in Study 1 (Bass and Avolio, 1992), which is the mainstay of transformational leadership research (Van Knippenberg and Sitkin, 2013) and a different and industry specific measure in Study 2 (Geijsel et al., 2009). Using different measures across contexts provides evidence in favour of 
the generality of our findings. The converging positive results revealed in this research reinforce our view that transformational leadership research remains a research topic of major theoretical and practical significance.

The use of subjective rating scales to measure knowledge sharing and innovative behaviour was another limitation of our study. As observed by Reiter-Palmon, RobinsonMorral, Kaufman and Santo (2012), subjective reports of creative accomplishment should be interpreted cautiously when used as a criterion. In our study, we chose to measure innovative behaviour (as opposed to creativity) to account for the creation, promotion and implementation of novel ideas. Nonetheless, our data do not show what kinds of innovations were being developed (e.g., products, services, methods), nor whether their quality and implementation were superior under a low or high transformational leader. Thus, it is recommended that future studies use objective records of innovative implementation where possible.

The effect of knowledge sharing as a mediator between transformational leadership and innovative behaviour was consistent across the two studies. This finding raises additional questions that could be addressed in future studies. One possibility is that knowledge sharing substitutes for the effects of transformational leadership, thereby acting as a moderator rather than a mediator. We tested an alternate model which included an interaction between transformational leadership and knowledge sharing; however, this was non-significant for Study $1(\beta=0.001, p=.998)$ and Study $2(\beta=-0.031, p=.648)$. Nonetheless, future studies may wish to investigate whether different forms of knowledge sharing influence the relationship between transformational leadership and innovative behaviour.

Another opportunity would be to distinguish the direction of knowledge sharing (i.e., providing versus receiving information). For example, receiving new information may stimulate new ideas, thereby facilitating innovative behaviour. On the other hand, sharing 
one's own ideas may help to refine them, as other employees can provide feedback about their feasibility and usefulness. Studies could also distinguish the effects of different types of knowledge exchange, such as knowledge validation or dissemination (cf. Bhatt, 2001). A second opportunity would be to distinguish the effects of knowledge sharing with specific parties (i.e., experts, customers, customers, suppliers and team mates) on a range of innovative outcomes. For example, knowledge sharing with team members may help to resolve day-to-day problems, whereas speaking with clients and customers may stimulate new ideas for products and services. A fourth opportunity would be to examine the relationship between knowledge sharing and innovative behaviour over a different time frame. In Study 2, the measures of each activity were taken over a year apart. The long interval between measurements may have concealed temporal relationships between these two activities.

\section{Implications and conclusion}

Despite these limitations, our two studies provide a robust test of the three hypotheses. By applying a two-wave, multi-actor design (Study 1) and a three-wave longitudinal design (Study 2), our study minimizes issues related to common method variance. Our conclusions are strengthened by the consistency of findings between the two studies, especially given the differences in the sampling strategy and rating scales used to measure key variables. Our second study also reveals that the positive effects of transformational leadership are longstanding, and that habitual knowledge sharing increases innovative behaviour.

Overall, our study offers several insights. It demonstrates that high levels of transformational leadership encourage knowledge sharing and innovative behaviour. This suggests that the subscales of transformational leadership (e.g., articulating a compelling vision) are less effective when they occur in isolation. Moreover, our study reveals the counterintuitive finding that knowledge sharing still occurs at very low levels of transformational leadership. It demonstrates that transformational leadership has curvilinear 
effects on knowledge sharing among employees and between teams, and that both forms are strongly linked to innovative behaviour. This finding may explain why transformational leadership is effective in some situations and not others. Ultimately, our study suggests that low and high transformational leadership enhances the open exchange of information, thereby stimulating innovative behaviour.

\section{References}

Amabile, T. M., R. Conti, H. Coon, J. Lazenby and M. Herron (1996). 'Assessing the work environment for creativity', Academy of Management Journal, 39, pp. 1154-1184.

Anderson, N., K. Potočnik and J. Zhou (2014). 'Innovation and creativity in organisations: A state-of-the-science review, prospective commentary, and guiding framework', Journal of Management, 40, pp. 1297-1333.

Argote, L., B. McEvily and R. Reagans (2003). 'Managing knowledge in organisations: An integrative framework and review of emerging themes', Management Science, 49, pp. 571-582.

Bakkenes, I., J. D. Vermunt and T. Wubbels (2010). 'Teacher learning in the context of educational innovation: Learning activities and learning outcomes of experienced teachers', Learning and Instruction, 20, pp. 533-548.

Bass, B. M. (1985). Leadership and performance beyond expectations, Free Press, New York.

Bass, B. M. (1990). 'From transactional to transformational leadership: Learning to share the vision', Organisational Dynamics, 18, pp. 19-31.

Bass, B. M. and B. J. Avolio (1992). Multifactor Leadership Questionnaire-Short Form 6S, Binghampton, NY, Center for Leadership Studies.

Basu, R. and S. G. Green (1997). 'Leader-member exchange and transformational leadership: An empirical examination of innovative behaviors in leader-member dyads', Journal of Applied Social Psychology, 27, pp. 477-499.

Bednall, T. C., K. Sanders and P. Runhaar (2014). 'Stimulating informal learning activities through perceptions of performance appraisal quality and HRM system strength: A two-wave study', Academy of Management Learning \& Education, 13, pp. 45-61.

Bhatt, G. D. (2001). 'Knowledge management in organisations: Examining the interaction between technologies, techniques, and people', Journal of Knowledge Management, 5, pp. 68-75.

Bliese, P. D. (2000). 'Within-group agreement, non-independence, and reliability: Implications for data aggregation and analysis'. In: K. J. Klein and S. W. J. Kozlowski (eds.), Multilevel theory, research and methods in organisations: Foundations, extensions, and new directions. pp. 349-381. San Francisco, CA: Jossey-Bass. 
Bock, G.-W., R. W. Zmud, Y.-G. Kim and J.-N. Lee (2005). 'Behavioral intention formation in knowledge sharing: Examining the roles of extrinsic motivators, socialpsychological forces, and organisational climate', MIS Quarterly, 29, pp. 87-111.

Boland, R. J. and R. V. Tenkasi (1995). 'Perspective making and perspective taking in communities of knowing', Organisation Science, 6, pp. 350-372.

Cabrera, Á., W. C. Collins and J. F. Salgado (2006). 'Determinants of individual engagement in knowledge sharing', The International Journal of Human Resource Management, 17, pp. 245-264.

Cole, D. A., N. C. Martin and J. H. Steiger (2005). 'Empirical and conceptual problems with longitudinal trait-state models: Introducing a trait-state-occasion model', Psychological Methods, 10, pp. 3-20.

Connelly, B. L., S. T. Certo, R. D. Ireland and C. R. Reutzel (2010). 'Signaling theory: A review and assessment', Journal of Management, 37, pp. 39-67.

Cook, T. and D. Campbell (1979). Quasi-experimentation: Design and analysis issues for field settings, Houghton Mifflin, Boston.

Damanpour, F. and M. Schneider (2008). 'Characteristics of innovation and innovation adoption in public organisations: Assessing the role of managers', Journal of Public Administration Research and Theory, 19, pp. 495-522.

De Jong, J. P. J. and D. N. Den Hartog (2005). 'Determinanten van Innovatief Gedrag: Een Onderzoek onder Kenniswerkers in het MKB (Determinants of innovative behaviour: an investigation among knowledge workers in SMEs)', Gedrag \& Organisatie, 18, pp. $235-259$.

Edmondson, A. C. (1999). 'Psychological safety and learning behavior in work teams', Administrative Science Quarterly, 44, pp. 350-383.

Eisenbeiss, S. A. and S. Boerner (2010). 'Transformational leadership and R\&D innovation: Taking a curvilinear approach', Creativity and Innovation Management, 19, pp. 364372.

Eisenbeiss, S. A. and S. Boerner (2013). 'A double-edged sword: Transformational leadership and individual creativity', British Journal of Management, 24, pp. 54-68.

Eisenbeiss, S. A., D. van Knippenberg and S. Boerner (2008). 'Transformational leadership and team innovation: Integrating team climate principles', Journal of Applied Psychology, 93, pp. 1438-1446.

Ellis, S. and I. Davidi (2005). 'After-event reviews: drawing lessons from successful and failed experience', Journal of Applied Psychology, 90, pp. 857-871.

Enders, C. K. (2001). 'A primer on maximum likelihood algorithms available for use with missing data', Structural Equation Modeling: A Multidisciplinary Journal, 8, pp. 128141. 
Frey, B. S. (1993). 'Motivation as a limit to pricing', Journal of Economic Psychology, 14, pp. 635-664.

Gagné, M. (2009). 'A model of knowledge-sharing motivation', Human Resource Management, 48, pp. 571-589.

García-Morales, V. J., M. M. Jiménez-Barrionuevo and L. Gutiérrez-Gutiérrez (2012). 'Transformational leadership influence on organisational performance through organisational learning and innovation', Journal of Business Research, 65, pp. 10401050.

García-Morales, V. J., F. J. Lloréns-Montes and A. J. Verdú-Jover (2008). 'The effects of transformational leadership on organisational performance through knowledge and innovation', British Journal of Management, 19, pp. 299-319.

Garvin, D. A., A. C. Edmondson and F. Gino (2008). 'Is yours a learning organisation?', Harvard Business Review, 86, pp. 109-116.

Geijsel, F. P., P. J. C. Sleegers, R. D. Stoel and M. L. Krüger (2009). 'The effect of teacher psychological and school organisational and leadership factors on teachers' professional learning in Dutch schools', The Elementary School Journal, 109, pp. 406427.

Gilson, L. L. and C. E. Shalley (2004). 'A little creativity goes a long way: An examination of teams' engagement in creative processes', Journal of Management, 30, pp. 453-470.

Gong, Y., J. C. Huang and J. L. Farh (2009). 'Employee learning orientation, transformational leadership, and employee creativity: The mediating role of employee creative selfefficacy', Academy of Management Journal, 52, pp. 765-778.

Gumusluoglu, L. and A. Ilsev (2009). 'Transformational leadership, creativity, and organisational innovation', Journal of Business Research, 62, pp. 461-473.

Gumusluoğlu, L. and A. Ilsev (2009). 'Transformational leadership and organisational innovation: The roles of internal and external support for innovation', Journal of Product Innovation Management, 26, pp. 264-277.

Hamaker, E. L., R. M. Kuiper and R. P. Grasman (2015). 'A critique of the cross-lagged panel model', Psychological Methods, 20, pp. 102-116.

Hammond, M. M., N. L. Neff, J. L. Farr, A. R. Schwall and X. Zhao (2011). 'Predictors of individual-level innovation at work: A meta-analysis', Psychology of Aesthetics, Creativity, and the Arts, 5, pp. 90-105.

Hoffman, B. (2005). Informal Learning, ASTD Press, Alexandria, USA.

Hou, H.-T., Y.-T. Sung and K.-E. Chang (2009). 'Exploring the behavioral patterns of an online knowledge-sharing discussion activity among teachers with problem-solving strategy', Teaching and Teacher Education, 25, pp. 101-108.

Hox, J. J. (2010). Multilevel analysis: Techniques and applications, Routledge, New York. 
Hsu, M.-H., T. L. Ju, C.-H. Yen and C.-M. Chang (2007). 'Knowledge sharing behavior in virtual communities: The relationship between trust, self-efficacy, and outcome expectations', International Journal of Human-Computer Studies, 65, pp. 153-169.

Hu, L. and P. M. Bentler (1999). 'Cutoff criteria for fit indexes in covariance structure analysis: Conventional criteria versus new alternatives', Structural Equation Modeling, 6, pp. 1-55.

Hu, M.-L. M., J.-S. Horng and Y.-H. C. Sun (2009). 'Hospitality teams: Knowledge sharing and service innovation performance', Tourism Management, 30, pp. 41-50.

Ipe, M. (2016). 'Knowledge sharing in organisations: A conceptual framework', Human Resource Development Review, 2, pp. 337-359.

Jackson, C. J. (2010). 'Introducing the YWeDo online cognitive laboratory'. In: S. Boag and N. Tiliopoulos (eds.), Personality and individual differences: Theory, assessment, and application. pp. 283-293. New York, NY: Nova.

Janssen, O. (2005). 'The joint impact of perceived influence and supervisor supportiveness on employee innovative behaviour', Journal of Occupational and Organisational Psychology, 78, pp. 573-579.

Jaussi, K. S. and S. D. Dionne (2003). 'Leading for creativity: The role of unconventional leader behavior', The Leadership Quarterly, 14, pp. 475-498.

Jimenez-Jimenez, D. and R. Sanz-Valle (2012). 'Studying the effect of HRM practices on the knowledge management process', Personnel Review, 42, pp. 28-49.

Jung, D. I. and B. J. Avolio (2000). 'Opening the black box: An experimental investigation of the mediating effects of trust and value congruence on transformational and transactional leadership', Journal of Organisational Behavior, 21, pp. 949-964.

Jung, D. I., C. Chow and A. Wu (2003). 'The role of transformational leadership in enhancing organisational innovation: Hypotheses and some preliminary findings', The Leadership Quarterly, 14, pp. 525-544.

Jung, T. and K. A. S. Wickrama (2008). 'An introduction to latent class growth analysis and growth mixture modeling', Social and Personality Psychology Compass, 2, pp. 302317.

Kahai, S. S., J. J. Sosik and B. J. Avolio (2003). 'Effects of leadership style, anonymity, and rewards on creativity-relevant processes and outcomes in an electronic meeting system context', The Leadership Quarterly, 14, pp. 499-524.

Kerr, S. and J. M. Jermier (1978). 'Substitutes for leadership: Their meaning and measurement', Organisational Behavior and Human Performance, 22, pp. 375-403.

Klein, A. and H. Moosbrugger (2000). 'Maximum likelihood estimation of latent interaction effects with the LMS method', Psychometrika, 65, pp. 457-474.

Laforet, S. (2008). 'Size, strategic, and market orientation affects on innovation', Journal of Business Research, 61, pp. 753-764. 
Lakshman, C. (2005). 'Top executive knowledge leadership: Managing knowledge to lead change at general electric', Journal of Change Management, 5, pp. 429-446.

LeBreton, J. M. and J. L. Senter (2007). 'Answers to 20 questions about interrater reliability and interrater agreement', Organisational Research Methods, 11, pp. 815-852.

Liao, S. h., W. C. Fei and C. C. Chen (2007). 'Knowledge sharing, absorptive capacity, and innovation capability: An empirical study of Taiwan's knowledge-intensive industries', Journal of Information Science, 33, pp. 340-359.

Lin, H.-F. (2007a). 'Effects of extrinsic and intrinsic motivation on employee knowledge sharing intentions', Journal of Information Science, 33, pp. 135-149.

Lin, H.-F. (2007b). 'Knowledge sharing and firm innovation capability: An empirical study', International Journal of Manpower, 28, pp. 315-332.

Little, T. D. (2013). Longitudinal Structural Equation Modeling, The Guildford Press, New York.

Little, T. D., W. A. Cunningham, G. Shahar and K. F. Widaman (2002). 'To parcel or not to parcel: Exploring the question, weighing the merits', Structural Equation Modeling, 9, pp. 151-173.

Little, T. D., D. W. Slegers and N. A. Card (2006). 'A non-arbitrary method of identifying and scaling latent variables in SEM and MACS models', Structural Equation Modeling, 13, pp. 59-72.

Lykken, D. T. (1968). 'Statistical significance in psychological research', Psychological Bulletin, 70, pp. 151-159.

McArdle, J. J. (2009). 'Latent variable modeling of differences and changes with longitudinal data', Annual Review of Psychology, 60, pp. 577-605.

Mumford, M. D., G. M. Scott, B. Gaddis and J. M. Strange (2002). 'Leading creative people: Orchestrating expertise and relationships', The Leadership Quarterly, 13, pp. 705-750.

Nyström, H. (1990). Organisational innovation, John Wiley \& Sons, Oxford, England.

Pieterse, A. N., D. Van Knippenberg, M. Schippers and D. Stam (2009). 'Transformational and transactional leadership and innovative behavior: The moderating role of psychological empowerment', Journal of Organisational Behavior, 31, pp. 609-623.

Pillai, R., E. A. Williams, K. B. Lowe and D. I. Jung (2003). 'Personality, transformational leadership, trust, and the 2000 U.S. presidential vote', The Leadership Quarterly, 14, pp. 161-192.

Rafferty, A. E. and M. A. Griffin (2004). 'Dimensions of transformational leadership: Conceptual and empirical extensions', The Leadership Quarterly, 15, pp. 329-354.

Reiter-Palmon, R., E. J. Robinson-Morral, J. C. Kaufman and J. B. Santo (2012). 'Evaluation of self-perceptions of creativity: Is it a useful criterion?', Creativity Research Journal, 24, pp. 107-114. 
Renzl, B. (2008). 'Trust in management and knowledge sharing: The mediating effects of fear and knowledge documentation', Omega: The International Journal of Management Science, 36, pp. 206-220.

Runhaar, P., K. Sanders and H. Yang (2010). 'Stimulating teachers' reflection and feedback asking: An interplay of self-efficacy, learning goal orientation, and transformational leadership', Teaching and Teacher Education, 26, pp. 1154-1161.

Sanders, K. and C.-H. V. Lin (2016). 'Human resource management and innovative behaviour: Considering interactive, informal learning activities'. In: H. Shipton, P. Budhwar, P. Sparrow and A. Brown (eds.), Human Resource Management, Innovation and Performance. pp. 32-47. Hampshire, UK: Palgrave Macmillan.

Sanders, K. and H. Shipton (2012). 'The relationship between transformational leadership and innovative behaviour in a healthcare context: A team learning versus a cohesion perspective', European Journal of International Management, 6, pp. 83-100.

Sarros, J. C., B. K. Cooper and J. C. Santora (2008). 'Building a climate for innovation through transformational leadership and organisational culture', Journal of Leadership \& Organisational Studies, 15, pp. 145-158.

Scott, S. G. and R. A. Bruce (1994). 'Determinants of innovative behavior: A path model of individual innovation in the workplace', Academy of Management Journal, 37, pp. 580-607.

Senge, P. M. (1997). 'The Fifth Discipline', Measuring Business Excellence, 1, pp. 46-51.

Shalley, C. E. (1995). 'Effects of coaction, expected evaluation, and goal setting on creativity and productivity', Academy of Management Journal, 38, pp. 483-503.

Smith, K. G., C. J. Collins and K. D. Clark (2005). 'Existing knowledge, knowledge creation capability, and the rate of new product introduction in high-technology firms', Academy of Management Journal, 48, pp. 346-357.

Van den Hooff, B. and J. A. de Ridder (2004). 'Knowledge sharing in context: the influence of organisational commitment, communication climate and CMC use on knowledge sharing', Journal of Knowledge Management, 8, pp. 117-130.

Van der Vegt, G. S. and O. Janssen (2003). 'Joint impact of interdependence and group diversity on innovation', Journal of Management, 29, pp. 729-751.

Van Knippenberg, D. and S. B. Sitkin (2013). 'A critical assessment of charismatictransformational leadership research: Back to the drawing board?', The Academy of Management Annals, 7, pp. 1-60.

Van Woerkom, M. (2003). 'Critical reflections at work. Bridging individual and organisational learning'. Enschede: University of Twente.

Wagner, E. R. and E. N. Hansen (2005). 'Innovation in large versus small companies: insights from the US wood products industry', Management Decision, 43, pp. 837-850. 
Walker, H. J., A. A. Armenakis and J. B. Bernerth (2007). 'Factors influencing organisational change efforts: An integrative investigation of change content, context, process and individual differences', Journal of Organisational Change Management, 20, pp. 761773.

Wang, S. and R. A. Noe (2010). 'Knowledge sharing: A review and directions for future research', Human Resource Management Review, 20, pp. 115-131.

West, M. A., G. Hirst, A. Richter and H. Shipton (2004). 'Twelve steps to heaven: Successfully managing change through developing innovative teams', European Journal of Work and Organisational Psychology, 13, pp. 269-299.

Widaman, K. F., E. Ferrer and R. D. Conger (2010). 'Factorial invariance within longitudinal structural equation models: Measuring the same construct across time', Child Development Perspectives, 4, pp. 10-18.

Wright, P. M., T. M. Gardner, L. M. Moynihan, H. J. Park, B. Gerhart and J. E. Delery (2001). 'Measurement error in research on human resources and firm performance: Additional data and suggestions for future research', Personnel Psychology, 54, pp. 875-901.

Yukl, G. (1999). 'An evaluation of conceptual weaknesses in transformational and charismatic leadership theories', The Leadership Quarterly, 10, pp. 285-305.

Zhu, Y. and S. Akhtar (2014). 'How transformational leadership influences follower helping behavior: The role of trust and prosocial motivation', Journal of Organisational Behavior, 35, pp. 373-392.

Zohar, D. and O. Tenne-Gazit (2008). 'Transformational leadership and group interaction as climate antecedents: A social network analysis', Journal of Applied Psychology, 93, pp. 744-757. 


\section{Tables}

Table 1.

Means, Standard Deviations, and Correlations among Variables

\begin{tabular}{lrrrrrr}
\hline \multicolumn{1}{c}{ Variable } & \multicolumn{1}{c}{ 1 } & \multicolumn{1}{c}{3} & 4 & 5 & \multicolumn{1}{c}{6} \\
\hline 1. Transformational leadership & - & & & & & \\
2. Knowledge sharing & $.31^{* *}$ & - & & & & \\
3. Innovative behaviour & $.37^{* * *}$ & $.56^{* * *}$ & - & & & \\
4. Manager tenure (years) & .08 & -.09 & .11 & - & & \\
5. Manager seniority & .20 & $.27 *$ & $.30^{* *}$ & .19 & - & \\
6. Company size & .11 & .17 & -.13 & .08 & .13 & - \\
\hline Means & 4.15 & 3.72 & 4.12 & 6.91 & 2.32 & 2.10 \\
SDs & 0.47 & 0.90 & 0.60 & 6.50 & 0.58 & 0.76 \\
Cronbach's alpha & .88 & .84 & .70 & n/a & n/a & n/a \\
$I C C(1)$ & .46 & .70 & .60 & n/a & n/a & n/a \\
$I C C(2)$ & .74 & .85 & .79 & n/a & n/a & n/a \\
Mean $r_{W G(J)}$ & .97 & .89 & .95 & n/a & n/a & n/a \\
\hline
\end{tabular}

Note. Team level correlations are presented. For manager seniority, $1=$ team leader, $2=$ junior manager, $3=$ senior manager. For company size, $1=1-20$ people, $2=21-100$ people, $3=100+$ people. $* p<.05, * * p<.01, * * * p<.001$ 
Table 2

Standardized Factor Loadings for the Confirmatory Factor Analysis (Study 1)

Factor

loading

Transformational Leadership

Idealized influence subscale .86

Individualized consideration subscale

Inspirational motivation

Intellectual stimulation subscale

Knowledge Sharing

Question stem: This unit has forums for meeting with and learning from:

Experts from other departments

Experts from outside the organisation $\quad .92$

Customers and clients $\quad .87$

$\begin{array}{lr}\text { Suppliers } & .88\end{array}$

$\underline{\text { Innovative Behaviour }}$

Idea generation subscale $\quad .95$

Idea promotion subscale $\quad .88$

$\begin{array}{ll}\text { Idea realization subscale } & .85\end{array}$

Note. For all factor loadings, $p<.001$. 
Running head: HOW MUCH TRANSFORMATIONAL LEADERSHIP DO YOU NEED?

Table 3.

Means, Standard Deviations, and Correlations among Variables

\begin{tabular}{|c|c|c|c|c|c|c|c|c|c|c|c|}
\hline Variable & Means & SDs & 1 & 2 & 3 & 4 & 5 & 6 & 7 & 8 & 9 \\
\hline 1. Gender & 0.66 & 0.47 & - & & & & & & & & \\
\hline 2. Tenure & 6.34 & 1.69 & .09 & - & & & & & & & \\
\hline$\underline{\text { Wave } 1}$ & & & & & & & & & & & \\
\hline 3. Transformational Leadership & 3.33 & 0.92 & .02 & -.09 & $(.89)$ & & & & & & \\
\hline 4. Knowledge Sharing & 3.78 & 0.71 & -.07 & -.03 & $.27 * * *$ & $(.82)$ & & & & & \\
\hline $\begin{array}{l}\text { 5. Innovative Behaviour } \\
\text { Wave } 2\end{array}$ & 3.90 & 0.62 & -.02 & -.02 & .09 & $.42 * * *$ & $(.79)$ & & & & \\
\hline 6. Knowledge Sharing & 3.77 & 0.67 & -.07 & -.11 & $.33 * * *$ & $.57 * * *$ & $.32 * * *$ & $(.81)$ & & & \\
\hline $\begin{array}{l}\text { 7. Innovative Behaviour } \\
\text { Wave } 3\end{array}$ & 3.87 & 0.62 & -.05 & -.09 & .11 & $.26 * * *$ & $.55 * * *$ & $.39 * * *$ & $(.82)$ & & \\
\hline 8. Knowledge Sharing & 3.75 & 0.69 & .01 & -.07 & $.31 * * *$ & $.59 * * *$ & $.26 * * *$ & $.54 * * *$ & $.31 * * *$ & $(.83)$ & \\
\hline 9. Innovative Behaviour & 3.93 & 0.62 & .00 & -.10 & .07 & $.33 * * *$ & $.54 * * *$ & $.37 * * *$ & $.68 * * *$ & $.39 * * *$ & $(.81)$ \\
\hline
\end{tabular}

Note. $* p<.05, * * p<.01, * * * p<.001$. Cronbach's alpha reliability coefficients are presented in the diagonal. 
Running head: HOW MUCH TRANSFORMATIONAL LEADERSHIP DO YOU NEED?

Table 4

Standardized Factor Loadings for the Strict Invariance Measurement Model (Study 2)

Time 1 Time 2 Time 3

Transformational Leadership

Vision subscale

.80

Stimulation subscale

.84

Support subscale

Knowledge Sharing

I discuss with my team members what I think is important in my job

$\begin{array}{lll}.79 & .77 \quad .78\end{array}$

I discuss with my team members our criteria for functioning well

$\begin{array}{lll}.75 & .73 & .73\end{array}$

I discuss problems in my classroom teaching with others in order to learn

from them

I discuss my development with my team members

$\underline{\text { Innovative Behaviour }}$

I come up with creative solutions for problems

$\begin{array}{lll}.61 & .57 \quad .58\end{array}$

I go searching for new methods and ways to work

$.62 \quad .59 \quad .60$

I promote and defend my innovative ideas to others

$\begin{array}{lll}.86 & .84 & .84\end{array}$

I try to convince colleagues of alternatives ways to work

.77

.74

.75

Note. For all factor loadings, $p<.001$. Although the unstandardized factor loadings were constrained to be equal across waves $1-3$, the standardized loadings vary due to differences in the variances of each item over time. 


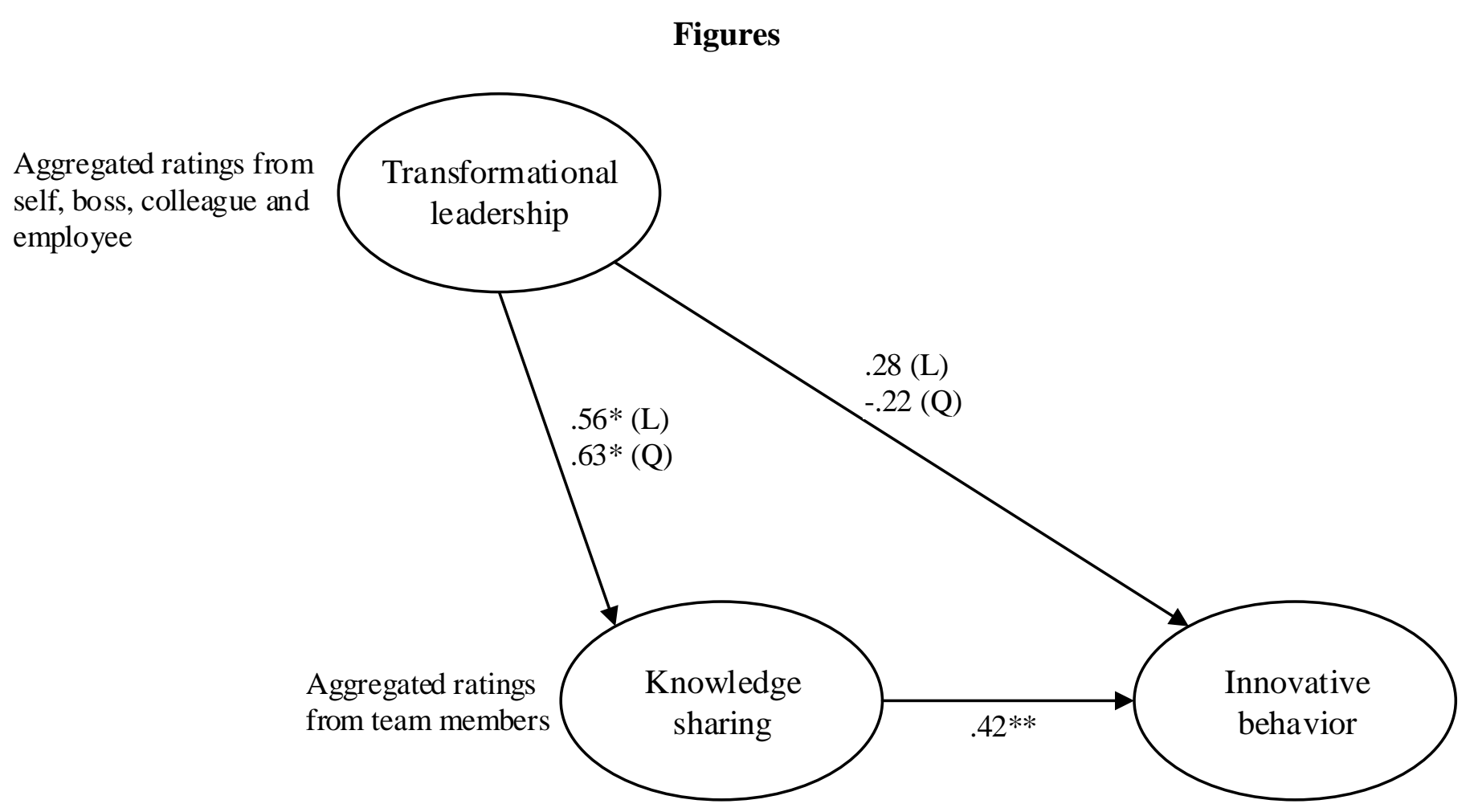

Figure 1. Structural model depicting the relationship between transformational leadership, knowledge sharing and innovative behaviour. Linear and quadratic effects are referred to by $(\mathrm{L})$ and $(\mathrm{Q})$ respectively. The linear effect also represents the gradient of the predicted curve at the mean of transformational leadership. Unstandardized regression coefficients are presented. $* p<.05, * * p<.01$. 


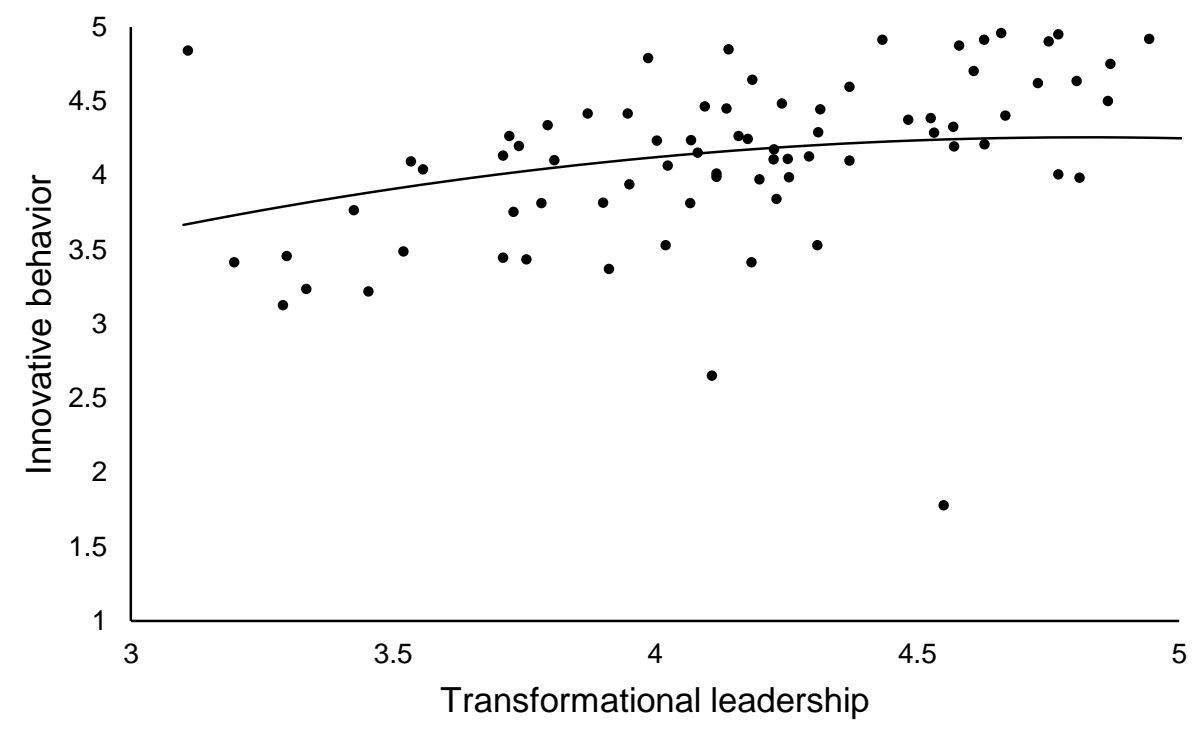

A: Effect of transformational leadership on innovative behaviour

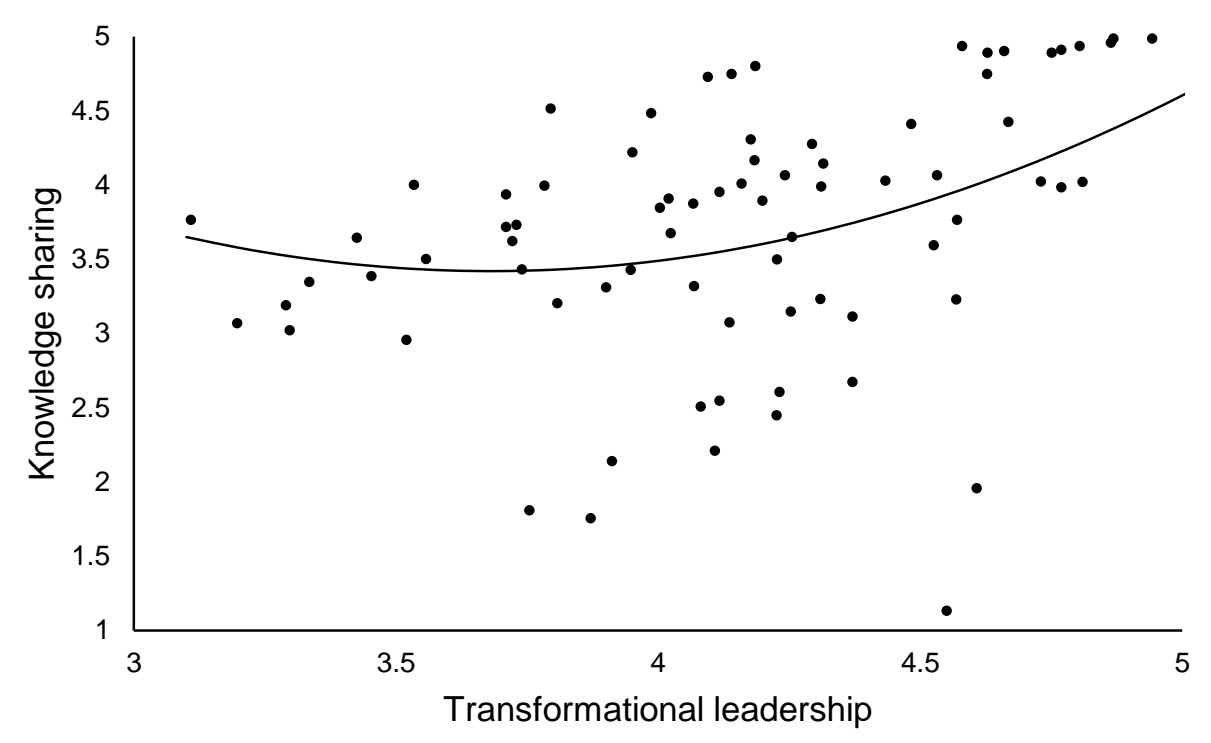

B: Effect of transformational leadership on knowledge sharing

Figure 2. Effects of transformational leadership on innovative behaviour and knowledge sharing (Study 1). We presented the results in their original metric using the effects coding method of Little, Slegers and Card (2006). This method produces identical model fit and effect sizes as the standard scaling method (in which the first factor loading of each latent variable is fixed to 1$)$. 


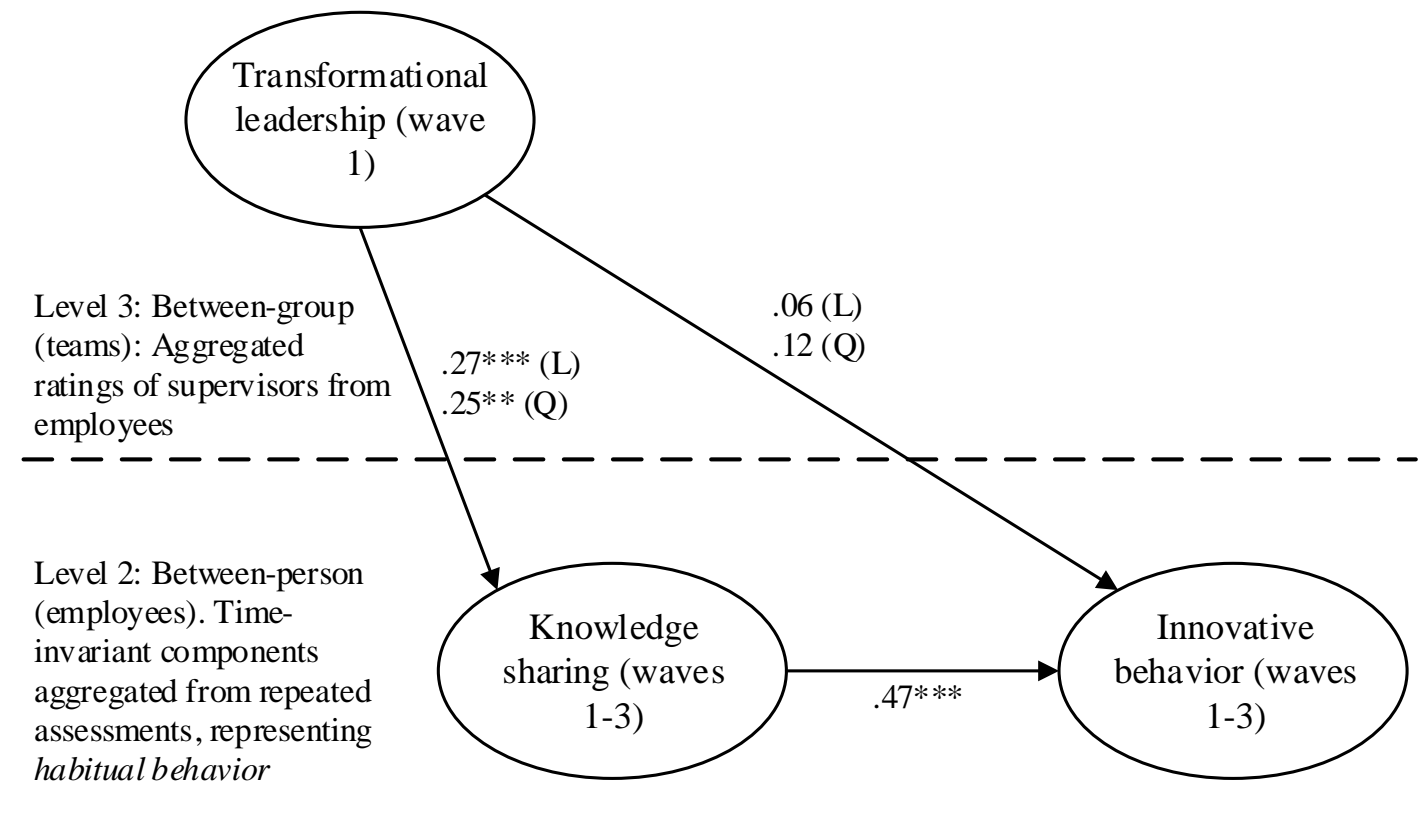

Level 1: Within-person (repeated assessments). Timevarying component, representing intermittent behavior

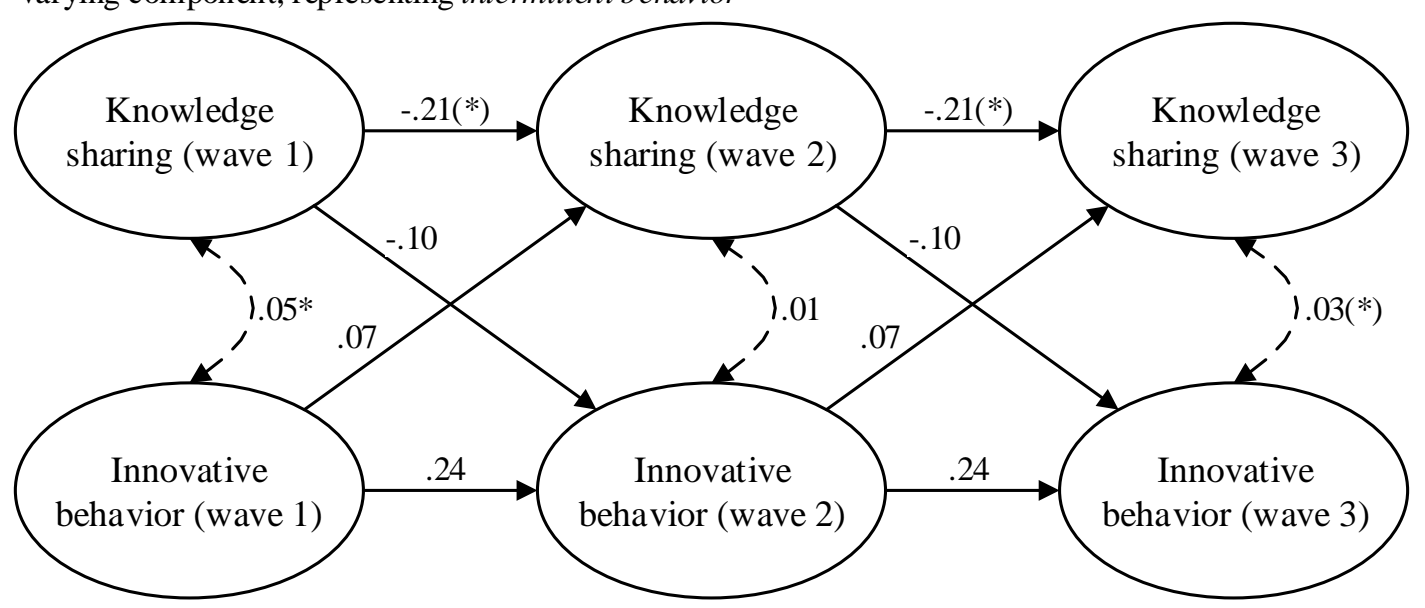

Figure 3. Random intercepts cross-lagged panel model (RI-CLPM) of the effects of transformational leadership on knowledge sharing and innovative behaviour (Study 2). Linear and quadratic effects are referred to by $(\mathrm{L})$ and $(\mathrm{Q})$ respectively. (L) represents the linear effect at the mean of transformational leadership. For this analysis, we used observed means in place of latent variables, as Mplus was unable to estimate the fully latent model with the required number of free parameters. At Level 1, the model accounted for $4.7 \%$ of the variance in knowledge sharing and 6.6\% in knowledge sharing; at Level 2, it accounted for $11.7 \%$ in knowledge sharing and $28.9 \%$ in innovative behaviour. To identify the model, the autoregressive and cross-lagged paths were constrained to equality over time. $* p<.05$, ** $p<.01 ., * * * p<.001$. 


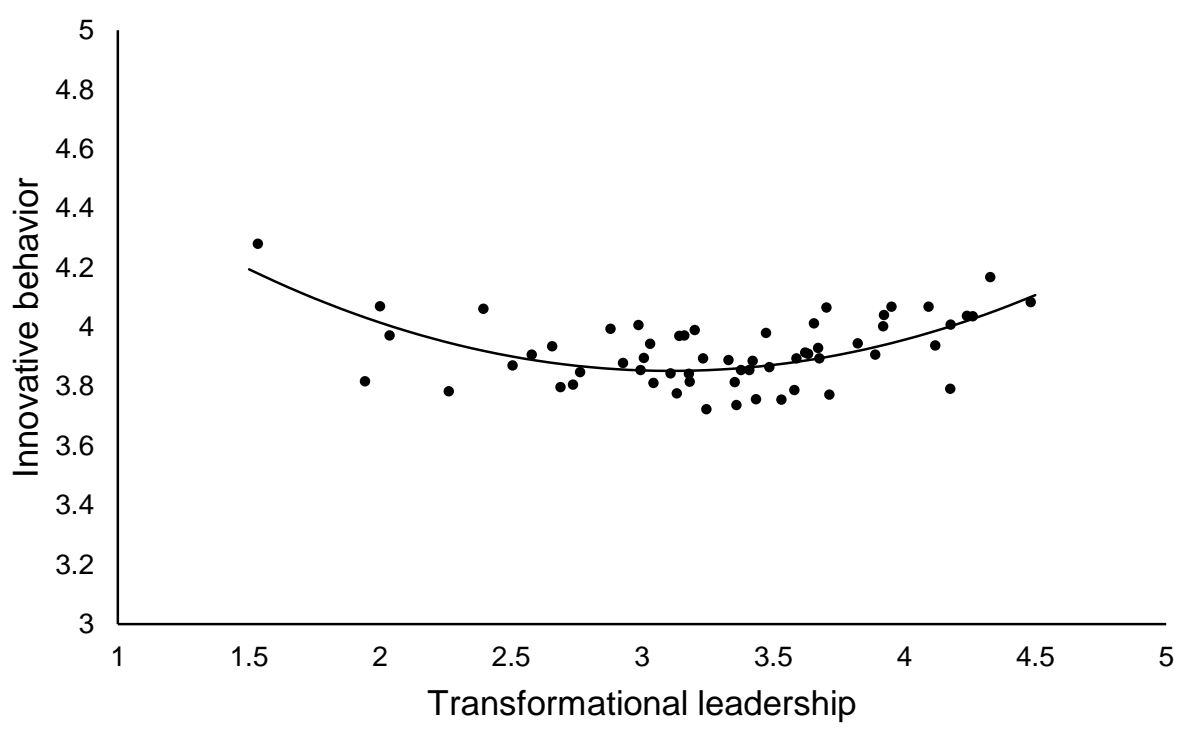

A: Effect of transformational leadership on innovative behaviour

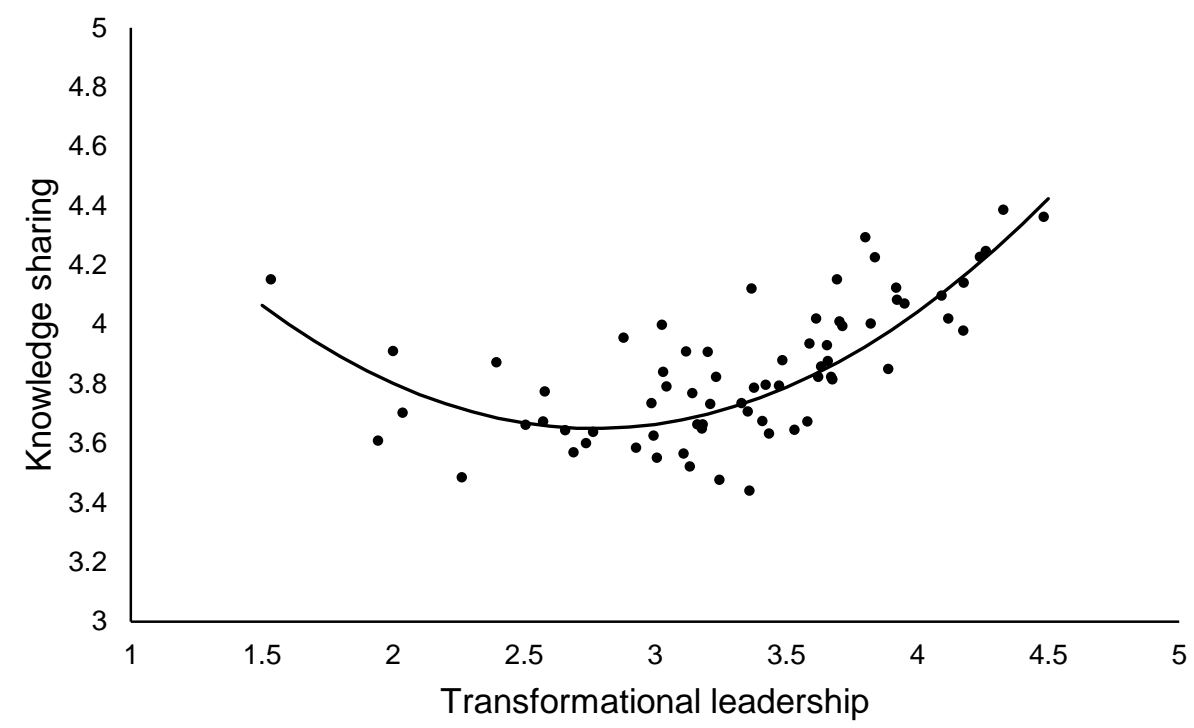

B: Effect of transformational leadership on knowledge sharing

Figure 4. Effects of transformational leadership on innovative behaviour and knowledge sharing (Study 2). 
Running head: HOW MUCH TRANSFORMATIONAL LEADERSHIP DO YOU NEED?

\section{Appendix 1: Measurement Invariance Testing}

To test the hypothesized factor structure over time and test for measurement invariance, we used the approach recommended by Widaman et al. (2010). We first tested a configural invariance model, in which the same factors and same items was tested at all three waves. The model yielded the following fit statistics: $\chi^{2}(\mathrm{df}=279)=389.367, \mathrm{CFI}=.972$, RMSEA $=.024$, SRMR $=.047$. Although the chi-square test was significant, the approximate indices of fit indicated a close fit to the data. Moreover, examination of the modification indices and residual covariance matrix revealed that residual correlations among the observed variables were small and unsystematic. With no strong theoretical grounds to re-specify the model, we retained the hypothesized measurement model.

In the next step, we tested a metric (weak) invariance model, in which the factor loadings of corresponding items were constrained to be equal across the three waves. This also yielded a close-fitting model, $\chi^{2}(\mathrm{df}=291)=411.391, \mathrm{CFI}=.970, \mathrm{RMSEA}=.025$, SRMR $=.054$. The Wald test of parameter constraints indicated that constraining the factor loadings did not result in significantly worse model fit, $\Delta \chi^{2}(\mathrm{df}=12)=19.315, p>.05$.

We then tested a scalar (strong) invariance model, in which the both the factor loadings and intercepts of corresponding items were constrained to be equal over the three waves. The latent variable means were freely estimated. This model similarly provided a close fit to the data: $\chi^{2}(\mathrm{df}=303)=420.355 ; \mathrm{CFI}=.971 ; \mathrm{RMSEA}=.024 ; \mathrm{SRMR}=.054$, and it did not worsen the fit from the metric invariance model $\Delta \chi^{2}(16)=9.754, p>.05$. Finally, we tested a strict invariance model, in which the residual variances of corresponding items were also constrained to be equal. This model also closely fitted the data: $\chi^{2}(\mathrm{df}=303)=420.355$, $\mathrm{CFI}=.971, \mathrm{RMSEA}=.024, \mathrm{SRMR}=.054$, and did not worsen the fit from the scalar invariance model, $\Delta \chi^{2}(\mathrm{df}=16)=10.917, p>.05$. 